\title{
Knowledge, attitude, and practice of obesity among university students
}

\author{
Baohong Xue ${ }^{1}$, Xu Zhang ${ }^{1}$, Tingting Li $^{1}$, Yuanlong Gu ${ }^{2}$, Rui Wang ${ }^{3}$, Wangyang Chen ${ }^{4}$ Xiaohua Ren ${ }^{4}$, \\ Xiaohong Liu ${ }^{4}$, Guanqing Chen ${ }^{4}$, Yi Lin ${ }^{4}$, Chenchen Pan ${ }^{4}$, Wenying Zhao ${ }^{4}$, Tinghui $\mathrm{Li}^{4}$, Lianping $\mathrm{He}^{4}$, \\ Chunlei Han $^{5}$
}

${ }^{1}$ College of Experience Industry, Anhui Polytechnic University, Wuhu, China; ${ }^{2}$ Department of Oncology, Taizhou Municipal Hospital, Taizhou, China; ${ }^{3}$ Training Center for Comprehensive Quality and Ability of College Student, Anhui Institute of Information Technology, Wuhu, China; ${ }^{4}$ School of Medicine, Taizhou University, Taizhou, China; ${ }^{5}$ School of Public Health and Management, Binzhou Medical University, Yantai, China Contributions: (I) Conception and design: L He, Y Gu; (II) Administrative support: C Han, X Chen, W Chen; (III) Provision of study materials or patients: B Xue, X Zhang, T Li; (IV) Collection and assembly of data: R Wang, X Ren, G Chen, Y Lin, C Pan, W Zhao, T Li; (V) Data analysis and interpretation: All authors; (VI) Manuscript writing: All authors; (VII) Final approval of manuscript: All authors.

Correspondence to: Lianping He. School of Medicine, Taizhou University, Taizhou 318000, China. Email: lianpinghe@tzc.edu.cn; Yuanlong Gu. Department of Oncology, Taizhou Municipal Hospital, Taizhou 318000, China. Email: ylgu@tzc.edu.cn.

\begin{abstract}
Background: Obesity, as an epidemic disease, is distributed among all age groups, including children, adolescents, adults, and the elderly. The goal of this study was to investigate the knowledge, attitude, and practice (KAP) concerning obesity among university students.

Methods: In total, 1,317 questionnaires were filled out by 1,317 (466 male and 851 female) randomly selected students aged range from 16 to 24 . All participants agreed to provide personal information in this study. A self-designed questionnaire was applied to collect demographic characteristics and assess the KAP of obesity. Gender, height, weight, grade, sleep and income were included in the population questionnaire. Descriptive statistics was used to analyze the respondent rate of KAP among students.

Results: In the survey, $64.9 \%$ of respondents believed that obesity was a disease. Only a few people cared about their body shape. Most of the participants in the study had practices that were detrimental to their health, including irregular dieting (52.9\%), surfing the internet, and playing games $(58.5 \%)$ in their spare time.

Conclusions: This study identified that lacking knowledge of obesity was common among college students. Most respondents had a positive attitude about preventing obesity by focusing on dieting and exercise. Thus, education related to obesity should be strengthening among university students to translate attitude into practice.
\end{abstract}

Keywords: Knowledge; attitudes; practices; undergraduate; obesity

Submitted Feb 12, 2021. Accepted for publication Apr 23, 2021.

doi: $10.21037 /$ apm-21-573

View this article at: http://dx.doi.org/10.21037/apm-21-573

\section{Introduction}

Obesity, as an epidemic disease, is distributed among all age groups, including children, adolescents, adults, and the elderly (1). Rapidly rising obesity rates are leading to a growing number of diseases, which are becoming a major health crisis (2). Data from the World Health Organization indicated that the number of obese people in the world in
2016 was 3 times as high as that in 1975. In 2016, about 1.9 billion adults over the age of 18 were overweight, of whom more than 650 million were obese. In Switzerland, $11 \%$ of men and $9 \%$ of women are obese (3). In Europe generally, the prevalence of obesity in women and men is $23 \%$ and $20 \%$, respectively (3).

Obesity is harmful to health in many ways. For example, obese people are more likely to develop cardiovascular 
Table 1 Knowledge of obesity among undergraduates in Wuhu, China

\begin{tabular}{lc}
\hline Question & $N(\%)$ \\
\hline Do you think obesity is a disease? & $851(64.6)$ \\
Yes & $460(34.9)$ \\
No & \\
How do you define obesity? & $819(62.2)$ \\
Self-perception & $347(26.3)$ \\
By scientific calculation & $149(11.3)$ \\
Other evaluation & $142(10.8)$ \\
Do you know the BMl prescribed by the World Health Organization? \\
Very well & $608(46.2)$ \\
Somewhat familiar & $561(42.6)$ \\
Not at all familiar &
\end{tabular}

disease (4). Obesity weakens the digestive system and increases the risk of cancer (5). In addition, obesity causes many inconveniences in people's lives and may have detrimental psychological effects (6).

The risk factors for obesity include social environmental factors (7), psychological factors (8), and genetic factors (9). The rise in obesity can be explained by the following. First, the improvement of living standards has led to a large increase in the intake of high-fat foods (10). Furthermore, a greater proportion of jobs require less physical strength due to urbanization (11). More proximally, a low resting metabolic rate is the main cause of obesity (12). One study indicated that people who eat irregularly are more likely to suffer from obesity than the general population (13). A good psychological attitude is also helpful in the treatment of obesity (14). Therefore, healthy dieting and physical activities are beneficial to reducing weight.

The purpose of this cross-sectional study was to learn about the knowledge, attitude, and practice (KAP) concerning obesity among university students in Wuhu, China. In this study, lacking knowledge of obesity was common among students. Participants had a wide range of practices in their lives that led to obesity. However, most of the students have a good attitude towards preventing obesity in the study. We present the following article in accordance with the SURGE reporting checklist (available at http://dx.doi.org/10.21037/apm-21-573).

\section{Methods}

In total, 1,317 questionnaires were filled out by 1,317 (466 male and 851 female) randomly selected students aged range from 16 to 24 years old. The study conformed to the provisions of the Declaration of Helsinki (as revised in 2013). All participants agreed to provide personal information in this study.

\section{Questionnaire design and data collection}

A self-designed questionnaire was applied to collect demographic characteristics and assess the KAP of obesity. Gender, height, weight, grade, sleep and income were included in the population questionnaire. A total of 21 questions were included in the KAP questionnaire on obesity.

\section{Data handling and statistical analysis}

Data were collected from the questionnaire and entered into the analysis software. The files were reviewed and compared with the paper questionnaire to eliminate the risk of any errors. Frequency and relative frequency were calculated by SPSS 20 (IBM Corp.).

\section{Results}

\section{Demographic characteristics}

A total of 1,317 participants were included in the study (466 male and 851 female). Of these, $64.6 \%$ were female. The respondent rate of KAP related to the obesity of university students was obtained (Table 1). After the Chisquare test, it was concluded that the proportion of men and women in the survey showed that such a ratio was statistically significant for obesity $(\mathrm{P}<0.05)$.

\section{Knowledge and attitude related to obesity}

Of the 1,317 undergraduates, 851 (64.6\%) believed that obesity was a disease (Table 1). Of the respondents, 33.9\% said they were snacking, $36.8 \%$ thought they had a normal body shape, and $44.6 \%$ wanted to lose weight to stay fit (Table 2). 
Table 2 Attitude of obesity among undergraduates in Wuhu, China

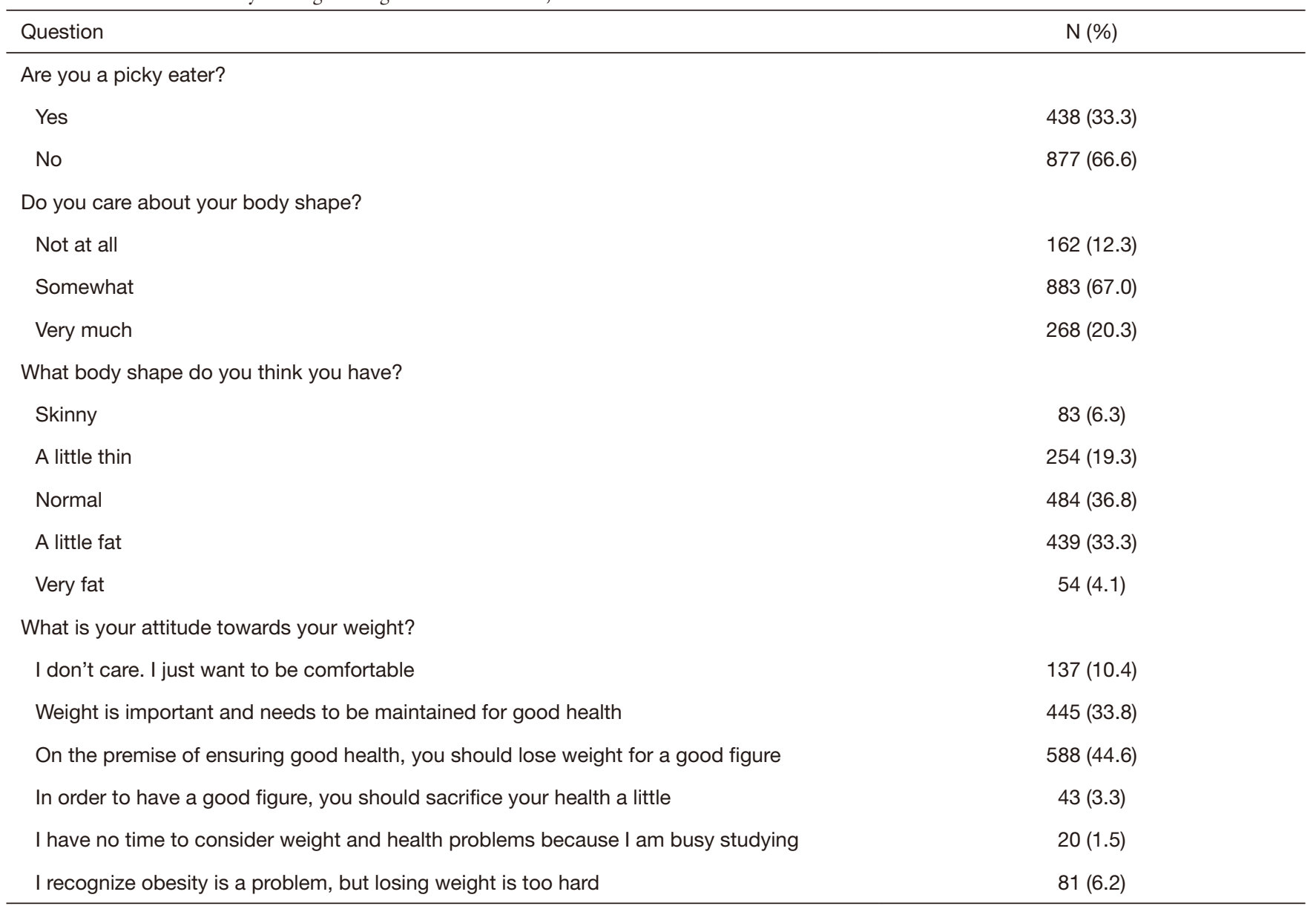

\section{Practices of participants on obesity}

Tables 3 and 4 summarize the practices of participants concerning obesity. Most of participants (63.5\%) ate breakfast more than 5 times a week. About $48.7 \%$ of the participants ate regularly at school but irregularly during the holidays. $46.7 \%$ of the students had regular eating habits. In addition to eating 3 meals a day, over $42 \%$ students ate afternoon tea or a late-night snack supper occasionally. Most of participants (93.5\%) claimed that they did not smoke, nearly half of the students $(46.7 \%)$ indicated that they drink occasionally every month, $78.1 \%$ of the participants said they did not have a green tea habit, $57 \%$ of students stated that they did not drink soda in the past 30 days, and over $34 \%$ participants indicated that they eat dessert 2-6 times a week. Most of the interviewees declared that they had not eaten at a Western fast-food restaurant in the past week. About $41.5 \%$ stated their food costs ranged between CNY 500 and CNY 700 every month. About
$43.9 \%$ of the students claimed that they often chose foods based on nutrition. Finally, about $37.4 \%$ of respondents indicated that they would eat a big meal if they were in a bad mood. Some of the subjects $(6.3 \%)$ did not eat even when hungry. In fact, $11.2 \%$ of the students had overeating behavior. The number of students who like to eat greasy food is not in the minority, with $68.6 \%$ of them. In fact the percentage of students who rarely eat vegetables and fruits. Excessive consumption of sugary foods is an important risk factor for health. However, $89.3 \%$ of people in the survey never avoided eating sugar. BMI and its associated risk factors were analyzed in Table 5.

\section{Discussion}

Obesity is one of the threats to good health. People with obesity are more willing to receive education about obesity than the general population. Overall, our survey results 
Table 3 Practices related to obesity in the past week among undergraduates in Wuhu, China

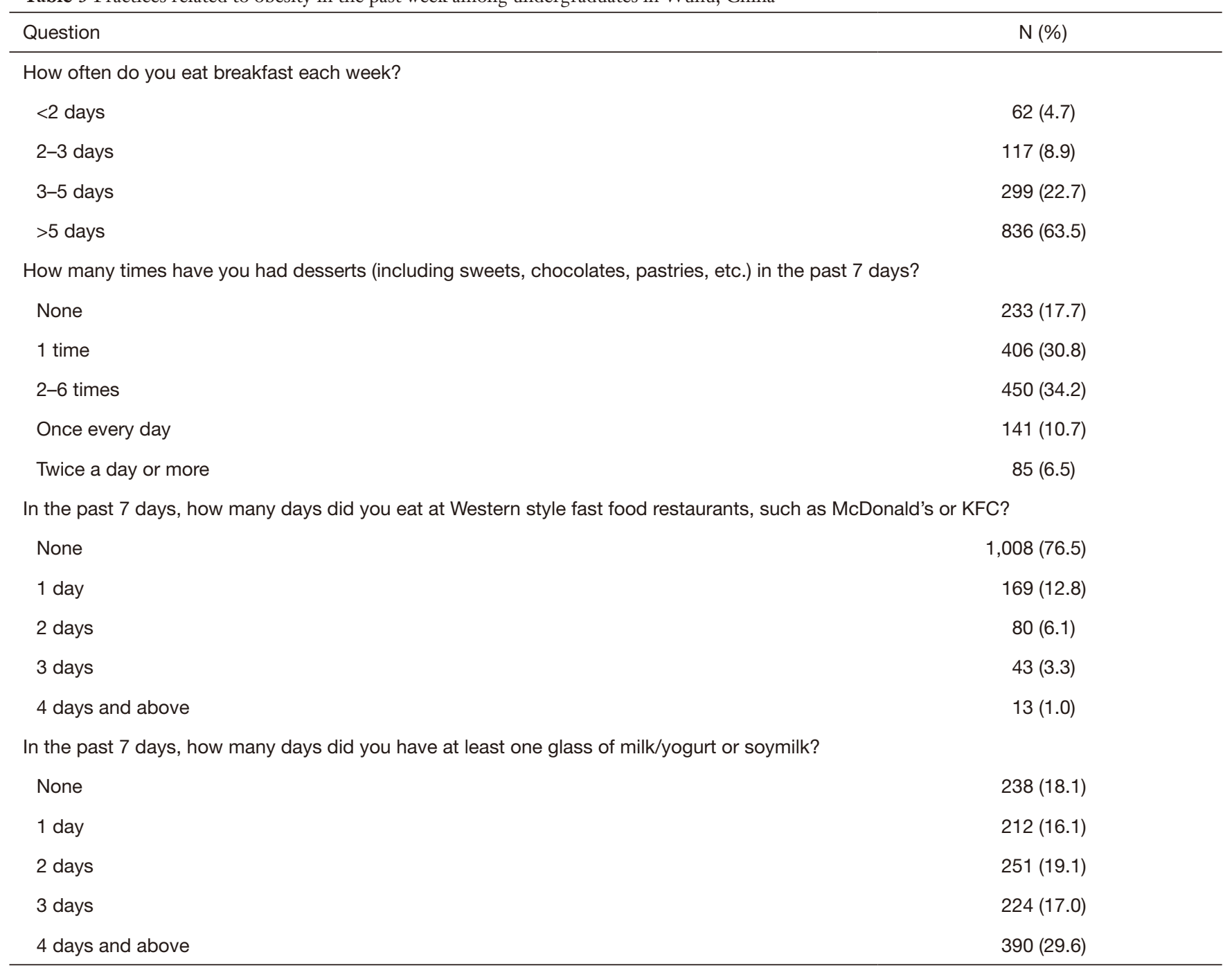

indicated that undergraduates have a poor knowledge about obesity. Most respondents had a vague definition of BMI which may be attributable in part to a general lack of general medical knowledge. Generally, however, the concept of obesity was unfamiliar to most interviewees, but most student's recognized obesity as a disease. It is necessary to strengthen the education about obesity to help undergraduates apply this knowledge to their daily habits and practices.

In this study, most participants had a positive attitude towards maintaining a healthy weight. Most of the students indicated that they were willing to control their weight in order to keep fit. However, this attitude was not generally reflected in their practice. In view of this, governments and schools should take relevant measures to translate this attitude into good practice.

An irregular dieting increases the burden on the body (15). For instance, skipping breakfast on weekends for an extended period may be bad for the digestive system (16). A result of study in South Africa indicated that irregular consumption of weekday breakfasts was associated with an increased risk of being overweight and obese among adolescents (15). Participants who eat afternoon tea or late-night snacks in addition to the regular 3 meals a day may have a higher rate of obesity. The result of our survey showed that nearly half of the students consider food without nutrients when eating. Eating sweets can increase the sugar content in the body which may contribute to 
Table 4 Practices of obesity in past month among undergraduates in Wuhu, China

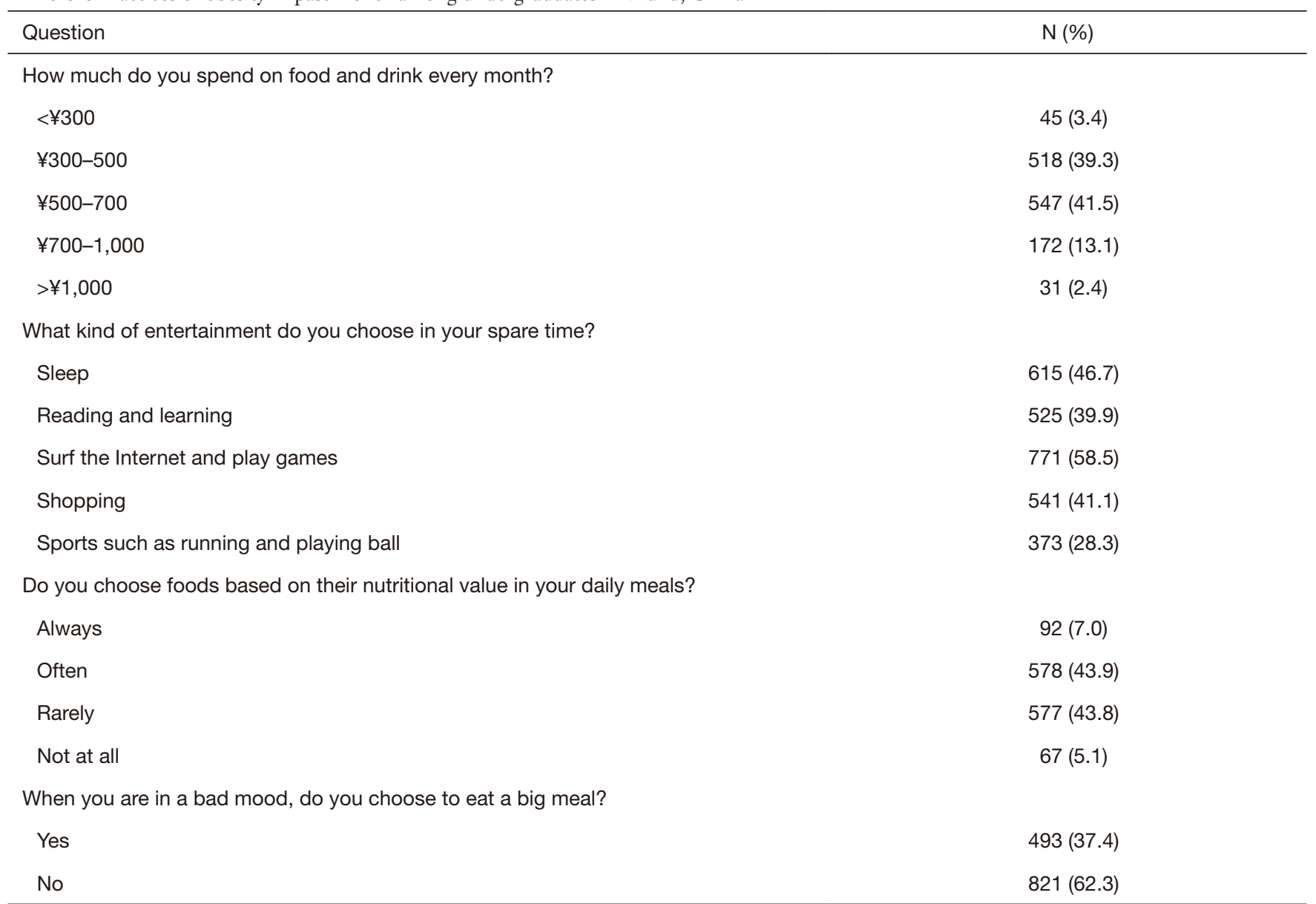

obesity (17).

Fortunately, western fast food was rarely eaten by college students. However, a similar study in Karachi, Pakistan, showed that a large proportion of participants preferred fried food (18). In a study in Pakistan, participants maintained a reasonable diet, rejected junk food, sugary, oily foods, finished dinner 6 hours before bed, and regularly engaged in physical activity to keep their body's BMI at a healthy level. Knowledge of obesity prevention was significantly associated with participants' attitude scores for BMI levels. One interesting result of our survey was that there were quite a few students who said they would eat a big meal to dispel a bad mood; however, they failed to consider that such behavior would make them gain weight (19). Another study found that children obesity is linked to parents, and that the government needs to create appropriate physical activity habits to change the family's beliefs and lifestyle to prevent and overcome problems such as childhood obesity. In contrast to the above, this study found that we compared college students with different academic qualifications, and found that there was no significant effect on the level of education compared to BMI $(\mathrm{P}>0.05)$.

In many epidemiological studies, sleep time has a little relationship with obesity. But in the study,347 people grew up with eight hours of sleep on weekends, 833 people who got less than eight hours of sleep, and there was no significant difference between getting sleep time and obesity $(\mathrm{P}>0.05)$. A comprehensive clinic in the United States measured 513 patients, including 169 obese and 196 overweight, and found that low levels of education were independently associated with obesity in subjects under the age of 30 , according to a cross-sectional study. The results also show that a lower relevant knowledge base is a risk factor for obesity development in young people. Formal education may have some meaning in maintaining a healthy weight. 
Table $5 \mathrm{BMI}$ and its associated risk factors

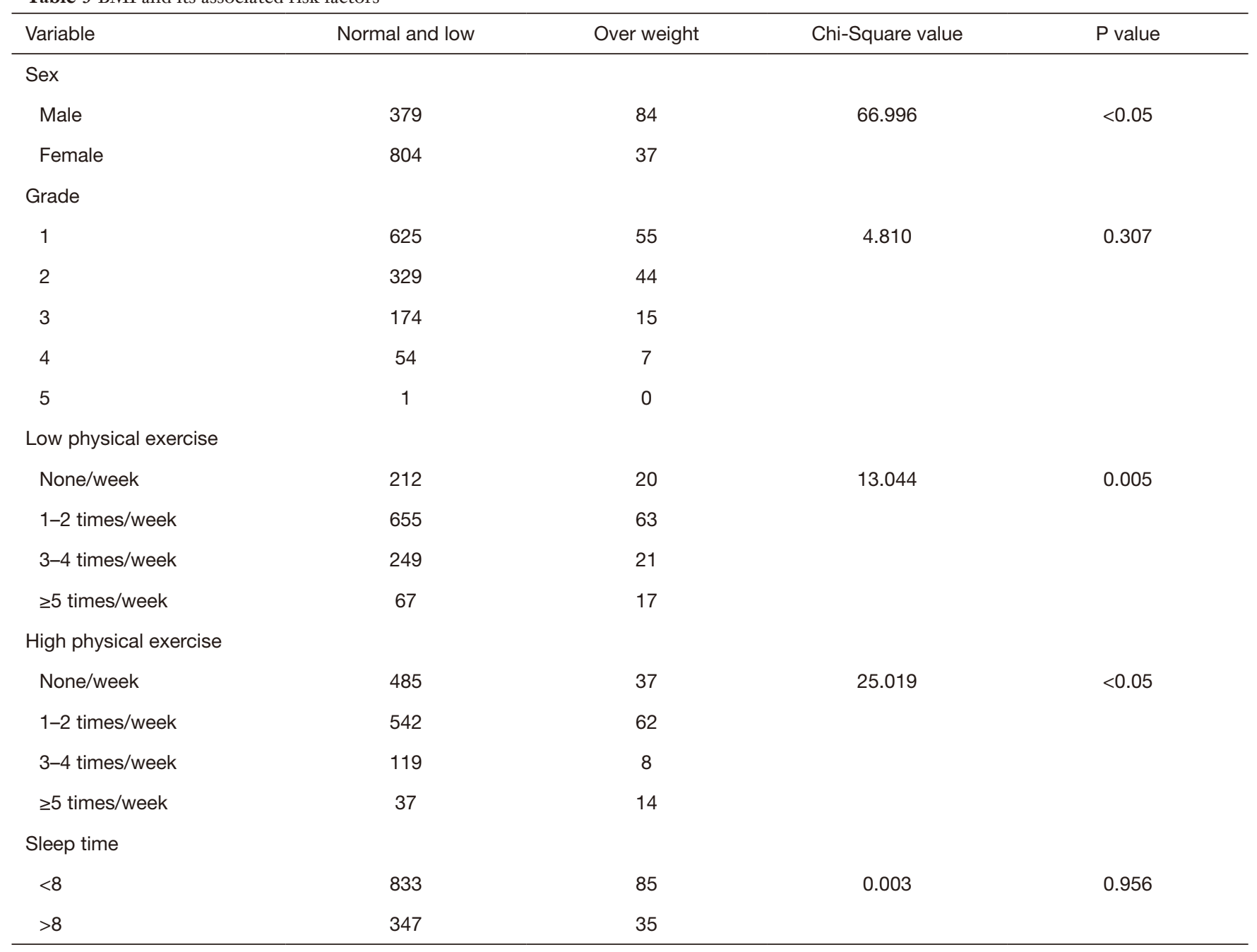

In the study of same-sex twins, participants from China's National Twin Registry (CNTR) had 10,448 pairs between the ages of 18 and 7. A regression analysis by the researchers concluded that overweight and obesity were associated with marital status and educational attention of both sexes. In women, the effect of education level on BMI was not related, but the level of education in men was associated with a higher risk of BMI, overweight and obesity.

In order to control the BMI index of college students, first of all, some students should get rid of the habit of overeating. Because regular overeating can lead to irregular diet, this does not help college students to maintain a healthy body. Second, people who often like to try greasy food without proper exercise, their body fat content will increase rapidly. Third, some college students should change the habit of eating junk food, puffed food, in other words, college students should pay attention to diet health. Fourth, as young people should strengthen physical exercise, maintain a reasonable amount of exercise every week, maintain physical vitality.

Some limitations of our study should be addressed. First, the gender ratio of participants was skewed in the study, with more female than male students. Second, as the questionnaire was self-designed, the results might have had errors or have been influenced by bias. The research population of this paper comes from the same university, which is also a limitation of the present study. In addition, the sample size was limited in the survey. 


\section{Conclusions}

The KAP of obesity among undergraduates should be strengthened in future. Most respondents had a positive attitude about preventing obesity by focusing on dieting and exercise. However, the results of our study suggested that transforming positive attitudes into practice still requires further work. Therefore, relevant departments in government and schools should pay more attention to this issue among students.

\section{Acknowledgments}

We would like to thank all the participants in our study. Funding: None.

\section{Footnote}

Reporting Checklist: The authors have completed the SURGE reporting checklist. Available at http://dx.doi. org/10.21037/apm-21-573

Data Sharing Statement: Available at http://dx.doi. org/10.21037/apm-21-573

Conflicts of Interest: All authors have completed the ICMJE uniform disclosure form (available at http://dx.doi. org/10.21037/apm-21-573). The authors have no conflicts of interest to declare.

Ethical Statement: The authors are accountable for all aspects of the work in ensuring that questions related to the accuracy or integrity of any part of the work are appropriately investigated and resolved. The study conformed to the provisions of the Declaration of Helsinki (as revised in 2013). All participants agreed to provide personal information in this study.

Open Access Statement: This is an Open Access article distributed in accordance with the Creative Commons Attribution-NonCommercial-NoDerivs 4.0 International License (CC BY-NC-ND 4.0), which permits the noncommercial replication and distribution of the article with the strict proviso that no changes or edits are made and the original work is properly cited (including links to both the formal publication through the relevant DOI and the license). See: https://creativecommons.org/licenses/by-nc$\mathrm{nd} / 4.0 /$.

\section{References}

1. Mabiala Babela JR, Nika ER, Nkounkou Milandou KG, et al. Knowledge, Attitudes, and Practices of Parents Facing Child and Adolescent Obesity in Brazzaville, Congo. Glob Pediatr Health 2016;3:2333794X16675546.

2. Cetinkaya S, Sert H. Sakarya University students' fat phobia levels and attitudes towards obese individuals and their correlation with healthy lifestyle behaviours: Knowledge, attitude and practice (KAP) study. J Pak Med Assoc 2018;68:1358-62.

3. Bucher Della Torre S, Courvoisier DS, et al. Knowledge, attitudes, representations and declared practices of nurses and physicians about obesity in a university hospital: training is essential. Clin Obes 2018;8:122-30.

4. Ardahan M, Konal E. The prevalence of hypertension and obesity and effective factors: A cross-sectional bazaar study. J Pak Med Assoc 2019;69:1018-21.

5. Qidwai W, Azam SI. Knowledge, attitude and practice regarding obesity among patients, at Aga Khan University Hospital, Karachi. J Ayub Med Coll Abbottabad 2004;16:32-4.

6. Marchand A, Beauregard N, Blanc ME. Work and nonwork stressors, psychological distress and obesity: evidence from a 14-year study on Canadian workers. BMJ Open 2015;5:e006285.

7. Noriea AH, Patel FN, Werner DA, et al. A Narrative Review of Physician Perspectives Regarding the Social and Environmental Determinants of Obesity. Curr Diab Rep 2018;18:24.

8. Zamani B, Daneshzad E, Siassi F, et al. Association of plant-based dietary patterns with psychological profile and obesity in Iranian women. Clin Nutr 2020;39:1799-808.

9. Vasanth Rao VRB, Candasamy M, Bhattamisra SK. Obesity an overview: Genetic conditions and recent developments in therapeutic interventions. Diabetes Metab Syndr 2019;13:2112-20.

10. Adamec C. Ideas of beauty and high living standards in their relation to obesity. Zdrav Prac 1969;19:82-7.

11. Lavie CJ, Carbone S, Kachur S, et al. Effects of Physical Activity, Exercise, and Fitness on ObesityRelated Morbidity and Mortality. Curr Sports Med Rep 2019;18:292-8.

12. Martins C, Norsett-Carr A. Obesity Knowledge among Final-Year Medical Students in Norway. Obes Facts 2017;10:545-58.

13. Heshka S, Spitz A, Nunez C, et al. Obesity and risk of gallstone development on a $1200 \mathrm{kcal} / \mathrm{d}(5025 \mathrm{Kj} /$ 


\section{d) regular food diet. Int J Obes Relat Metab Disord 1996;20:450-4.}

14. Kim SY, Choi SH, Kim JD, et al. Korean Youth with Comorbid Allergic Disease and Obesity Show Heightened Psychological Distress. J Pediatr 2019;206:99-104.e4.

15. Khan A, Khan SR, Burton NW. Missing breakfast is associated with overweight and obesity in Bangladeshi adolescents. Acta Paediatr 2019;108:178-9.

16. Shafer PR, Borsky A, Ngo-Metzger Q, et al. The Practice Gap: National Estimates of Screening and Counseling for Alcohol, Tobacco, and Obesity. Ann Fam Med 2019;17:161-3.

17. Sedibe MH, Pisa PT, Feeley AB, et al. Dietary Habits and Eating Practices and Their Association with Overweight

Cite this article as: Xue B, Zhang X, Li T, Gu Y, Wang R, Chen W, Ren X, Liu X, Chen G, Lin Y, Pan C, Zhao W, Li T, He L, Han C. Knowledge, attitude, and practice of obesity among university students. Ann Palliat Med 2021;10(4):45394546. doi: 10.21037/apm-21-573 and Obesity in Rural and Urban Black South African Adolescents. Nutrients 2018;10:145.

18. Trude ACB, Surkan PJ, Cheskin LJ, et al. A multilevel, multicomponent childhood obesity prevention grouprandomized controlled trial improves healthier food purchasing and reduces sweet-snack consumption among low-income African-American youth. Nutr J 2018;17:96.

19. Qidwai W, Samani ZA, Azam I, et al. Knowledge, Attitude and Practice of Vitamin Supplementation among Patients visiting Out-Patient Physicians in a Teaching Hospital in Karachi. Oman Med J 2012;27:116-20.

(English Language Editor: J. Gray) 